\title{
Pengembangan Desain Lampu Bambu untuk Segmentasi Pasar Jepang dengan Fleksibelitas Cahaya dan Gesture Control
}

\author{
Yolanda Pungki Rahmadani and Primaditya Hakim \\ Departemen Desain Produk Industri, Fakultas Arsitektur Desain dan Perencanaan, \\ Institut Teknologi Sepuluh Nopember (ITS) \\ e-mail: ypungki8@gmail.com
}

\begin{abstract}
Abstrak-Pemanfaatan bambu sebagai produk kerajinan dengan nilai eksklusif masih kecil. Dari jenis bahan bambu apus dapat dikombinasikan teknik pengolahan bambu apus seperti teknik melingkar bambu, laminasi bambu dan batang bambu. Kebutuhan pencahayaan dekorasi rumah sebagai pendukung gaya hidup perkotaan ke atas dengan tren desain hijau semakin diminati. Dalam memperoleh karakteristik desain diperlukan metode persona. pilihan konsep dekorasi rumah untuk pencahayaan bambu adalah dalam bentuk Mengembangkan Modernisasi Nilai-Nilai Kearifan Lokal, dengan makna memanfaatkan kekayaan bahan bambu menjadi produk kerajinan modern dalam bentuk pencahayaan dekorasi rumah dengan desain post modern, bersama dengan cahaya fleksibilitas dan kontrol gerak sebagai fitur interaktif pada pencahayaan dekorasi rumah.
\end{abstract}

Kata Kunci-Bambu, Coiling, Green Design, Lampu, Interaktif.

\section{PENDAHULUAN}

$\mathrm{I}$ NDONESIA sebagai salah satu negara tropis di dunia memiliki potensi sumber daya bambu yang cukup besar. Kementerian Perindustrian mulai mengembangkan potensi industri berbasis bambu untuk menghasilkan nilai tambah, dan dapat digunakan untuk pakaian, makanan, tempat tinggal, energi, dan lingkungan [1]. Produk bambu dalam beberapa kasus cenderung dikaitkan dengan konotasi negatif, misalnya kualitas buruk, murah, kasar atau ditinggalkan dan hanya digunakan untuk membuat kerajinan tangan.

Tabel 1.

Karakteristik bambu apus

\begin{tabular}{ll}
\hline \hline & Karakteristik Gigantochloa apus \\
\hline Tinggi & $8-22 \mathrm{~m}$ \\
Diameter & $4-13 \mathrm{~m}$ \\
Habitat Tumbuh & clumper padat \\
Iklim & Tropis - Subtropis \\
Ketahanan & $2{ }^{\circ} \mathrm{C}$ \\
Asal & Asia Tenggara \\
\hline \hline
\end{tabular}

Berbagai teknik pengolahan pada bambu diantaranya bambu laminasi, bambu coiling, bambu bending, bambu ruji dan bambu bubut dapat menghasilkan produk eksklusif dengan kualitas kerajinan tinggi serta finishing yang baik. Dengan penggunaan bambu sebagai lighting home decor dapat memberikan aksen alami pada ruangan dan efek flash cahaya yang unik dan tetap nyaman untuk mata sesuai dengan kapasitas pencahayan standar [2].

\section{RUMUSAN MASALAH}

Pemanfaatan bambu sebagai produk craft dengan nilai yang eksklusif masih sedikit dijumpai, terdapat beberapa perusahaan yang mulai merintis produk craft dengan material bambu pada beberapa tahun terakhir ini. Material bambu perlu dikembangkan untuk menghasilkan produk modern craft yang bernilai jual tinggi dan eksklusif serta memiliki ketahanan yang baik.

\section{TINJAUAN PUSTAKA}

\section{A. Jenis Bambu}

Gigantochloa apus, juga dikenal sebagai String Bamboo atau Pring Tali, adalah bambu yang berumpun banyak, berada di wilayah tropis dan berasal dari Asia Tenggara. Bambu apus adalah bambu yang paling penting secara ekonomi di Jawa, terutama di industri kerajinan dan furniture [3].

$B$.

Bambu

Teknik Pengolahan

1.Bambu Coiling

Keterampilan dalam pembuatan pada bambu coiling merupakan jenis kerajinan yang sudah berlangsung selama berabad-abad di Vietnam. Bambu tersebut digulung dan dibentuk dengan tangan untuk membentuk mangkuk yang kemudian memiliki beberapa lapisan Varnish alami yang diaplikasikan untuk menghasilkan hasil alami yang menjaga keindahan bambu [4].

2.Bambu Ruji

Bambu ruji adalah batang dari bambu yang dibuat dengan cara dipotong dengan panjang tertentu dan dibelah kecil kecil sesuai kebutuhan, stick dari bambu dengan beragam jenis dan keperluannya dibutuhkan untuk hasil produksi yang cukup banyak, dengan memanfaatkan teknologi tepat guna masyarakat di pedesaan saat ini dapat menghasilkan jumlah produksi yang mumpuni [5].

\section{METODE PENELITIAN}

Bagan metode penelitian ini dapat dilihat pada Gambar 1. 1. Literatur Review

Tinjauan literatur digunakan untuk menyaring informasi dari sumber terkait, mengambil esensi penelitian dan proyek sebelumnya.

2. Observasi

Pengamatan memiliki tujuan untuk mengumpulkan informasi dasar, pengamatan membutuhkan pencerminan dan fenomena yang sistematis diantaranya manusia, artefak, lingkungan, peristiwa, perilaku dan interaksi.

3.Persona

Persona menggambarkan pola dasar menjadi bentuk representatif yang bertujuan untuk memanipulasi fokus 
desain, skenario, dan bantuan dalam komunikasi. Metode selanjutnya yang digunakan adalah percobaan bahan bambu dalam bentuk proses pengawetan, proses pembentukan, proses pewarnaan dan proses finishing.

Pada tahap persona digunakan untuk menentukan karakteristik pengguna sesuai dengan produk. Pada tahap eksperimental standardisasi spesies bambu yang digunakan, ukuran bambu dan ketebalan bambu. Proses eksperimental menggunakan teknik melingkar bambu, latice bambu dan batang bambu.

\section{Imageboard}

Imageboard dapat digunakan untuk mengkomunikasikan secara visual deskripsi yang penting mengenai estetika, gaya, pengguna, konteks maupun aspek lain dari makna desain yang ditargetkan.

\section{Quisionaire}

Kuisioner adalah instrumen survei yang dirancang untuk mengumpulkan informasi dari orang-orang tentang karakteristik, pikiran, perasaan, persepsi, perilaku, atau sikap mereka, pada umunya diwujudkan dalam bentuk tertuis.

\section{EKSPERIMEN}

Pada percobaan tahan melingkar bambu digunakan bilah bambu dengan panjang $60 \mathrm{~cm}$ lebar $1,5 \mathrm{~cm}$ dan tebal $1,5 \mathrm{~mm}$. teknik melingkar menggunakan prinsip proses pembentukan melingkar yang dapat membentuk lingkaran yang kuat. Untuk proses pewarnaan yang terdiri dari pewarna alami dan pewarna buatan, proses pewarnaan diterapkan pada bilah bambu dengan ketebalan $1,5 \mathrm{~mm}$ dan $3 \mathrm{~mm}$.

\section{STUDI DAN ANALISA}

\section{A. Persona}

Persona mendiskripsikan pola dasar perilaku pengguna ke dalam bentuk yang representatif yang bertujuan untuk memanusiakan fokus desain, skenario pengujian dan bantuan dalam komunikasi. Berikut adalah persona pengguna lighting home decor :

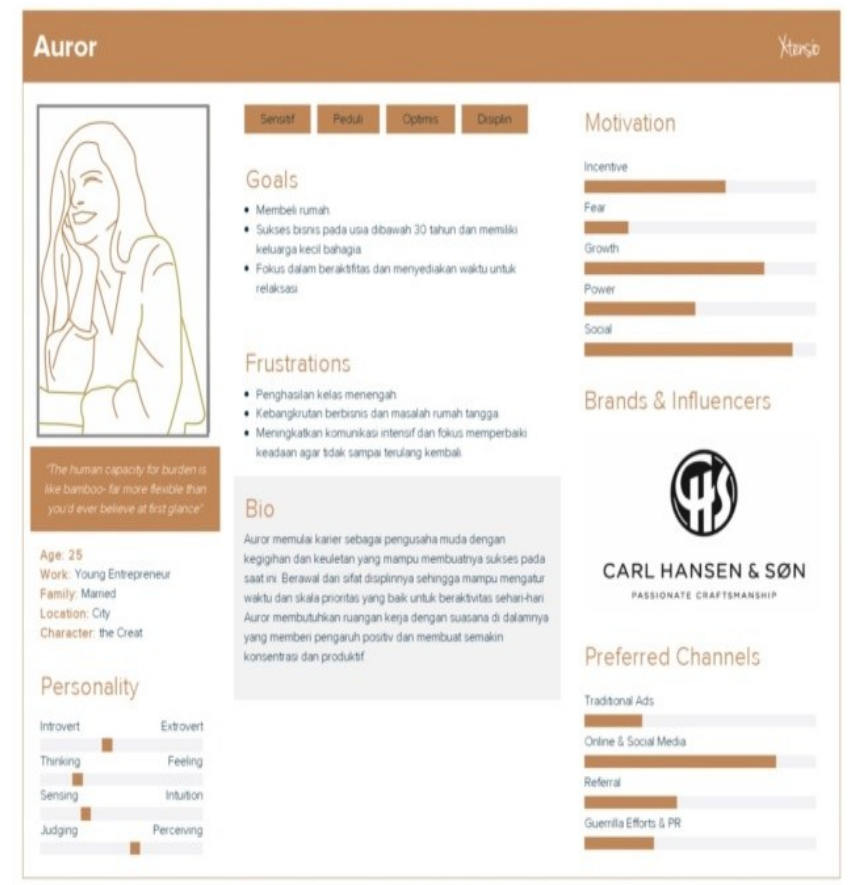

Gambar 1. Persona.
B. Studi Dan Analisa Segmenting, Targeting dan Positioning

Perbandingan pasar multidomestik dan pasar global dapat dilihat pada Tabel 2.

Tabel 2.

Perbandingan pasar multidomestik dan pasar global [6]

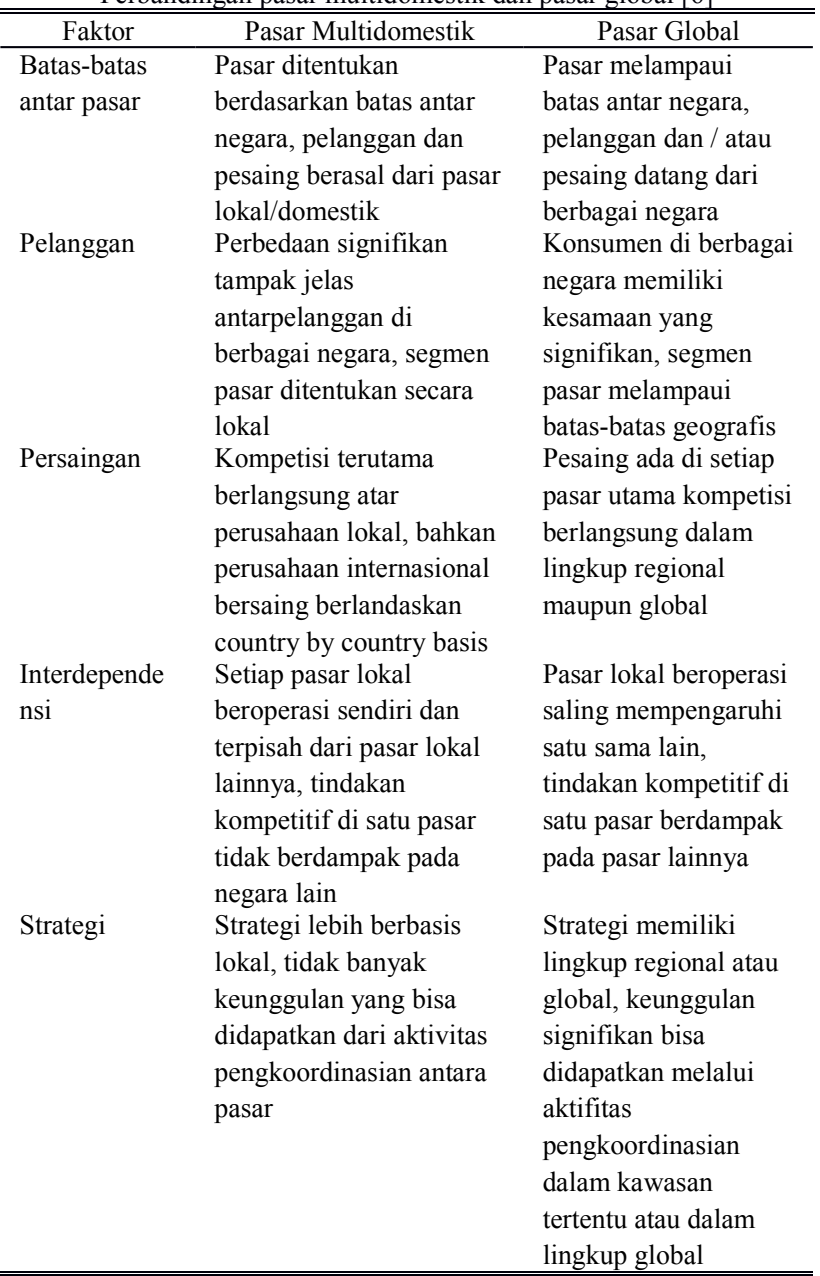

1. Segmenting

Dapat dlilihat pada Tabel 3.

2. Targeting

Penjelasan tentang targeting dapat dilihat pada Tabel 4.

3. Positioning

Positioning ditunjukkan pada Gambar 3.

\section{B. Gaya Hidup Masyarakat Jepang}

Populasi Jepang lebih dari 124m, 75\% di antaranya tinggal di daerah perkotaan seperti Tokyo, Yokohama, Kawasaki, Osaka, dan Nagoya. Perumahan berupa apartemen atau lebih dikenal oleh masyarakat Jepang. Rumah bergaya tradisional, dengan tikar jerami (tikar tatami) dan futon, dapat ditemukan di pinggiran kota, sementara perumahan gaya barat (dengan meja dan kursi) Menjadi lebih populer di kota-kota pedesaan. Jepang dinilai No. 11 dalam Indeks Kualitas Kehidupan PBB pada tahun 2010. Norwegia, Australia, Selandia Baru dan Amerika Serikat adalah empat negara peringkat teratas [7].

\section{Studi dan Analisa Trendforcasting 2018}

1. Svarga

Svarga adalah kata dalam bahasa sanskerta yang berarti 'surga', menggambarkan pendekatan antarmanusia secara spiritual. Profesor Yuval Noah Harari dalam bukunya yang 
mengundang kontroversi, Sapiens, menyatakan bahwa dalam sejarahnya, Homo sapiens berkembang ke arah saling ketergantungan dalam bidang politik dan ekonomi.

Tabel 3.

Segmenting

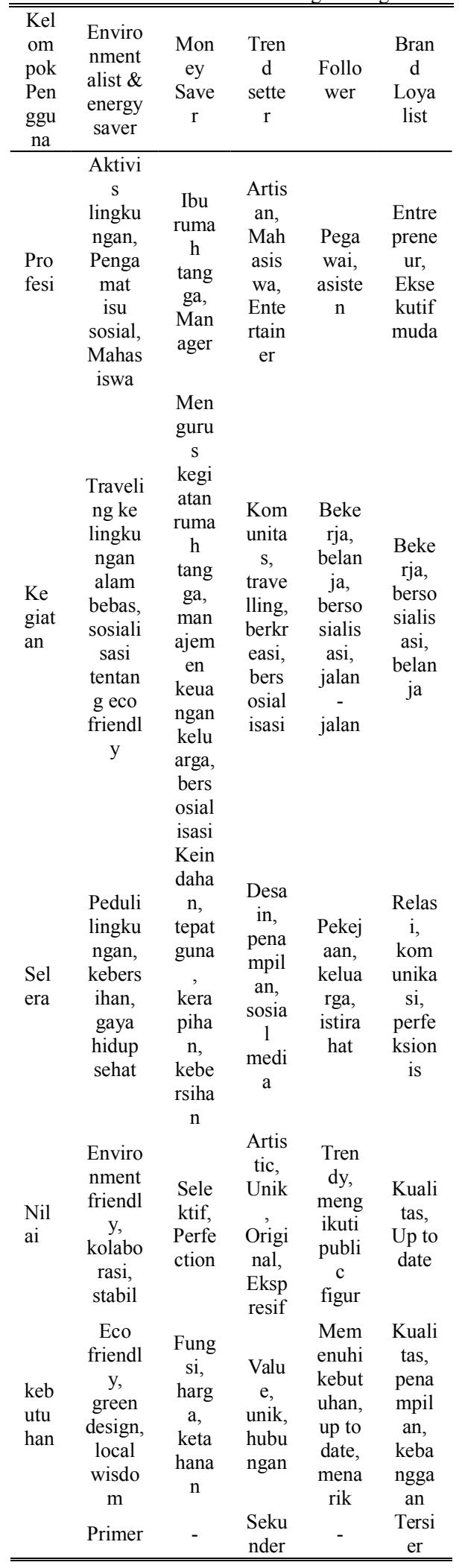

Tabel 4.

Targeting

\begin{tabular}{ccl}
\hline \hline No. & Jenis Demografi & \multicolumn{1}{c}{ Segmen Pasar } \\
\hline 1. & Jenis Kelamin & $\begin{array}{l}\text { Perempuan } \\
\text { Kota besar dengan populasi tinggi } \\
\text { dengan lingkungan alam yang } \\
\text { menarik seperti Tokyo. }\end{array}$
\end{tabular}
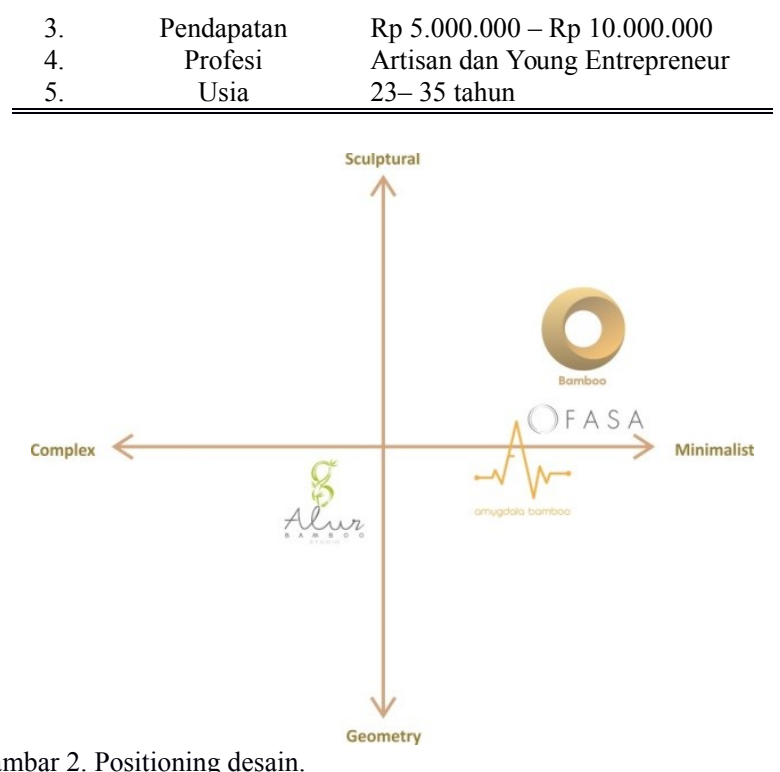

Gambar 2. Positioning desain.

Svarga merupakan simbol dari dampak yang bisa dihasilkan jika umat manusia bersatu dan bekerja sama, memberikan kemurahan hati dan pengetahuan dengan imbalan rasa bahagia, menciptakan semacam surga di atas bumi, mengurangi kerusakan dan penyakit sosial yang tercipta dari perjalanan sejarah umat manusia. Desain memperlihatkan produk-produk berbasis kriya bernilai tinggi untuk menggarisbawahi warisan tradisi yang tak ternilai harganya dan kearifan lokal pelaku kriya tradisional, yang eksistensinya kini sebagai penjaga budaya.

2. Svarga/ Upskill Craft

Natural material, Handcrafted, Community Empowerment, Glocalization. Subtema ini mendefinisikan kemewahan dengan memanfaatkan material natural maupun inovatif. Pembuatannya melibatkan desainer dan perajin berintelijensi tinggi dan memiliki pengetahuan material yang luas untuk menciptakan produk yang berkelas sesuai dengan gaya hidup tingkat tinggi. Produk yang dihasilkan merupakan sebuah transformasi menjadi produk-produk kontemporer bernilai tinggi.

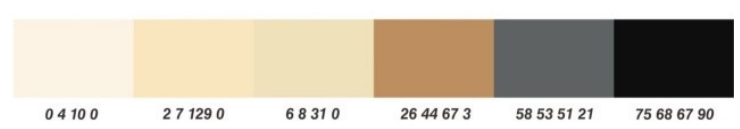

Gambar 3. Palet warna Svarga (Upskil Craft).

Material \& Teknik

:Material alami, buatan tangan, berbasis riset yang mendalam

Permukaan

:Tekstur alami dari material alami

Bentuk

:Organik terstruktur, meliuk

Pengalaman

:Kemewahan naturalis

\section{Studi dan Analisa Image Board Inspire}

\section{Square Board Idea}

Dalam menentukan konsep dapat diambil dari beberapa metode salah satunya dengan eksperiment dan observasi. Dari fenomena ketersediaan bambu yang melimpah, namun penerapan dalam segi produk dengan kualitas eksklusif cenderung sedikit. Ketersediaan bambu yang melimpah dan mudah didapat dapat meningkatkan value pada material. Dari segi eksperiment dapat diambil dengan tujuan untuk 
menonjolkan karakter dari material bambu. Maka konsep yang didapat adalah sebagai berikut:

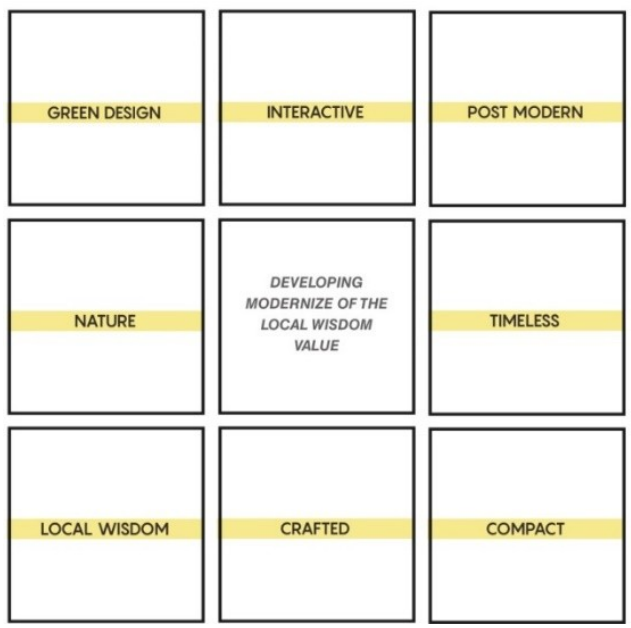

Gambar 4. Square board idea.

\section{Green Design}

Nilai green design dalam sub konsep tersebut tak lepas dari karakteristik material bambu sebagai tanaman yang eco friendly. Dengan pemanfaatan tanaman bambu secara efektif sekaligus dapat menjaga kelestarian tanaman bambu pada ekosistemnya sehingga dapat berkaitan erat dalam keberlanjutan desain.

\section{Nature}

Nilai natural dalam sub konsep tersebut berkaitan dengan bagian dasar material bambu yang dikenal sebagai tanaman yang berperan penting dalam kelestarian lingkungan. Dengan ini bambu dapat dimanfaatkan secara efektif untuk memenuhi kebutuhan produk bagi manusia dan tetap memperhatikan lingkungan natural pada alam.

\section{Local Wisdom}

Nilai local wisdom dalam sub konsep tersebut berhubungan dengan kearifan budaya lokal yang perlu diikutsertakan dalam implementasi pengembangan material bambu. Keterkaitan material bambu terhadap kehidupan sehari-hari pada masyarakat, bambu sudah menjadi bagian dalam kehidupan mereka Keterlibatan para pengrajin lokal untuk diedukasi dan saling bekerja sama dengan desainer kelak akan menghasilkan lingkungan kreatif yang dapat meningkatkan produktifitas masyarakat UKM [8].

\section{Crafted}

Nilai crafted dalam sub konsep tersebut berhubungan erat dengan proses dari pembuatan produk modern craft dengan material bambu. Proses terhadap bambu seperti coiling, laminasi dan stick sebagian besar akan dilakukan secara handmade dengan bantuan alat-alat penunjang produksi.

\section{Post Modern}

Nilai minimalis dalam sub konsep tersebut menghubungkan antara karakteristik material bambu yang dimaksimalkan dalam ekspos materialnya namun dengan memberi batasan berupa desain yang minimalis. Minimalis dalam artian jujur material, simple dalam bentuk desain, detail dalam memperhatikan teknik sambungan dan finishing dan tepat guna.

\section{Timeless}

Nilai timeless dalam sub konsep tersebut berhubungan dengan desain menggunakan material dasar bambu yang harus bisa bertahan tanpa terikat oleh tren pada masa-masa tertentu, sehingga dapat diaplikasikan sepanjang waktu dan tetap cocok untuk style interior yang yang beragam.

\section{Interaktif}

Nilai interactive dalam sub konsep tersebut sebagai inovasi tambahan dalam desain lampu agar terjalin interaksi antara pengguna ketika sedang menggunakan lampu tersebut. Interaksi dapat berupa gesture control oleh sensor pergerakan telapak tangan manusia, perpaduan bentuk lampu dan lain sebagainya.

\section{Material Board}

Dari material board tersebut diketahui dari teknik dasar bambu coiling dapat menghasilkan bentuk dasar lingkaran yang dapat diolah variasi bentuknya sesuai kebutuhan.

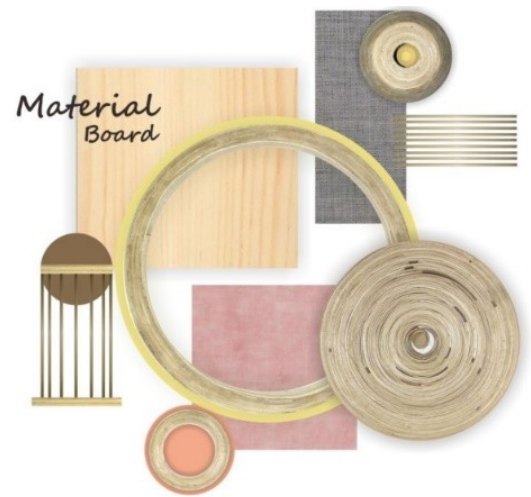

Gambar 5. Material board.

10. Analisa Desain Interior

Dekorasi interior Jepang berakar dari tradisi yang telah ada selama ribuan tahun. Dipandu oleh simbol dan keyakinan yang telah lama ada, gaya desain tersebut menjunjung tinggi ideal harmoni, keseimbangan, dan ketertiban, dan menempatkan nilai tinggi pada keindahan alam. Gaya Jepang menyampaikan rasa kesucian dan integritas yang seperti balsem bagi hidup kita yang penuh dengan kompleksitas. Hal tersebut sedikit eksotis dan misterius, namun dapat menghibur pada saat yang bersamaan.

\section{Objective Tree}

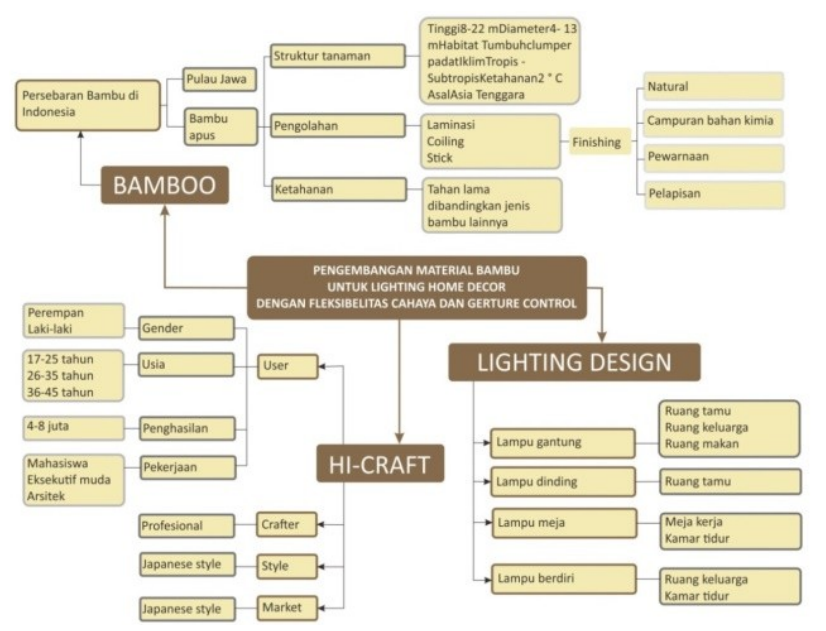

Gambar 6. Objective tree.

\section{PEMBAHASAN DESAIN}

\section{A. Konsep Bentuk}

Konsep bentuk menggunakan teori morfologi dan disesuaikan dengan konsep yang sudah ditentukan. Inspirasi desain lighting home decor terinspirasi oleh sangkar burung terutama hasil dari UKM wilayah Garut. Diketahui rangkaian sangkar terdiri dari bagian atas sangkar, jeruji 
penutup sangkar, kerangka pembentuk, slide pembuka sangkar, alas, dan bagian kaki. Dari bagian-bagian tersebut akan dieksplorasi dari masing-masing karakteristik part penyusun sangkar tersebut.

Pengolahan bentuk mempertimbangkan jenis teknik pada bambu yang diterapkan, mempertimbangkan ukuran yang seimbang dan sistematika pemasangan secara efisien.

\section{B. Alternatif Desain}

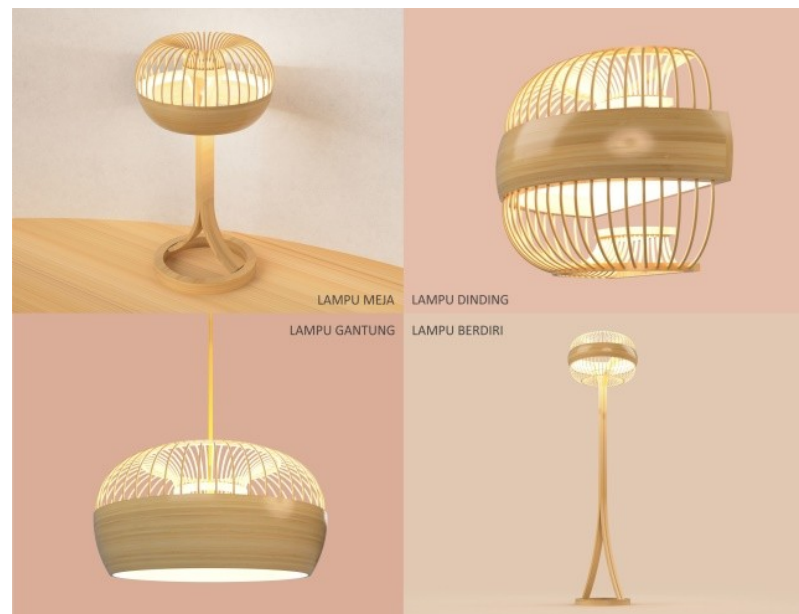

Gambar 7. 3D Rendering desain 1.

1. Desain series 1 dari segi bentuk tetap memperhatikan struktural dari sangkar burung, dengan bentukan dasar melingkar disertai kombinasi dari jeruji bambu. Tiap 1 series terdiri dari empat jenis lampu diantaranya lampu gantumg, lampu dinding, lampu meja dan lampu berdiri. Dari satu set desain lampu tersebut, komposisi bentuk memperlihatkan pengulangan yang serupa dalam empat jenis lampu tersebut dan disesuaikan dengan penerapan sesuai letaknya. Penggunaan jenis lampu pada series 1 berupa LED strip.

2. Desain series 2 dari segi bentuk tetap mengambil inspirasi dari part sangkar burung. Part utama yang diambil berupa bagian kaki dan alas sangkar, pada bagian tersebut teknik pengolahan bambu yang digunakan berupa bambu laminasi dan bending. Mulai dari komposisi bentuk dan tata letak lampu sesuai dengan inspirasi sangkar.

Komposisi pada desain lampu dibuat ringan, bersih dan minimalis, penggunaan jenis lampu berupa LED strip yang bisa menyesuaikan bentuk dari bending bambu. Penataan kabel dengan sedemikian rupa agar terlihat rapih dan bersih. Series kedua berupa satu set lampu diantaranya lampu gantung, lampu meja, lampu dinding dan lampu berdiri. Dari satu set desain lampu tersebut, komposisi bentuk memperlihatkan pengulangan yang serupa dalam empat jenis lampu tersebut dan disesuaikan dengan penerapan sesuai letaknya.

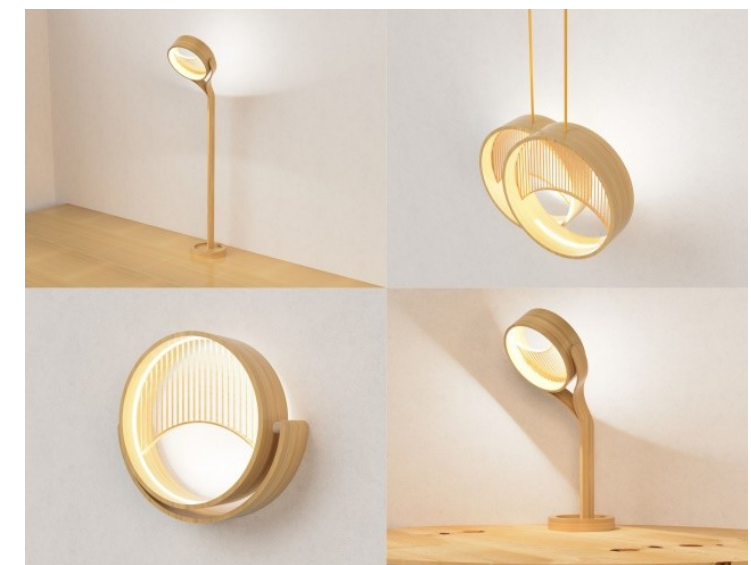

Gambar 8. 3D Rendering desain 2.

\section{Prototyping}

Proses pembuatan prototype dimulai dengan pemotongan bilah bambu yang kemudian diawetkan menggunakan cairan borax dan dikeringkan agar tahan terhadap rayap tanah dan kerapuhan [9]. Bilah bambu yang sudah kering kemudian diolah sesuai kebutuhan, diantaranya proses coiling dan bambu ruji sesuai pola cetakan desain lampu. Setelah dicetak sesuai pola cetakan, kemudian dirakit dan difinishing.

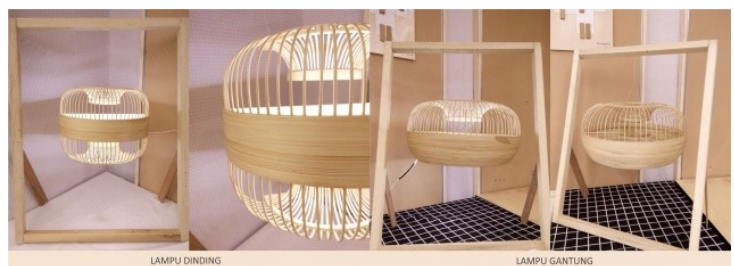

Gambar 9. Prototype.

\section{Tata Letak Lampu}

Proses pada perakitan lampu bambu yang sudah difinishing, dilanjutkan dengan pemasangan komponen elektronik berupa LED strip, kabel dan sensor arduino. Penempatan sensor arduino bisa diletakkan pada di sekitar kap lampu dan di area diluar lampu. Penggunaan sensor lampu diaplikasikan dengan cara menggerakkan telapak tangan di atas sensor tersebut dan untuk mengatur intensitas bisa digunakan dengan menggerakkan telapak tangan mendekati sensor [6].

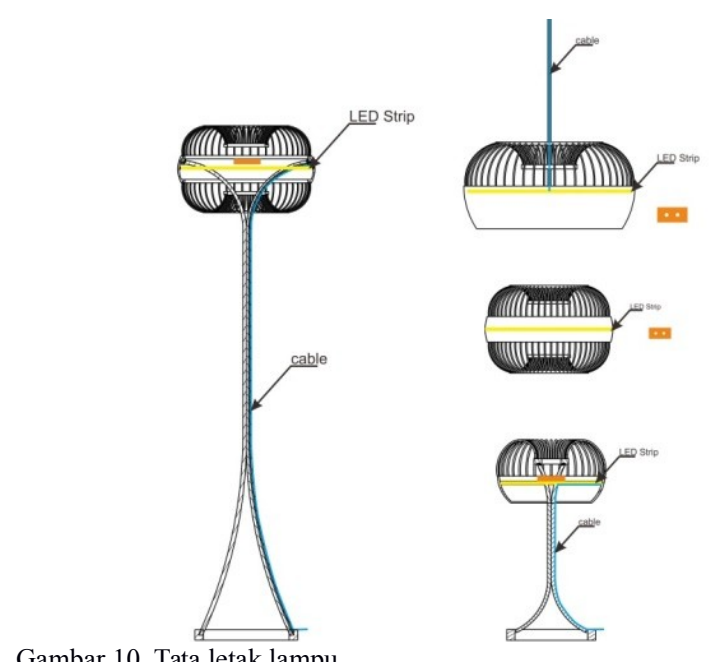




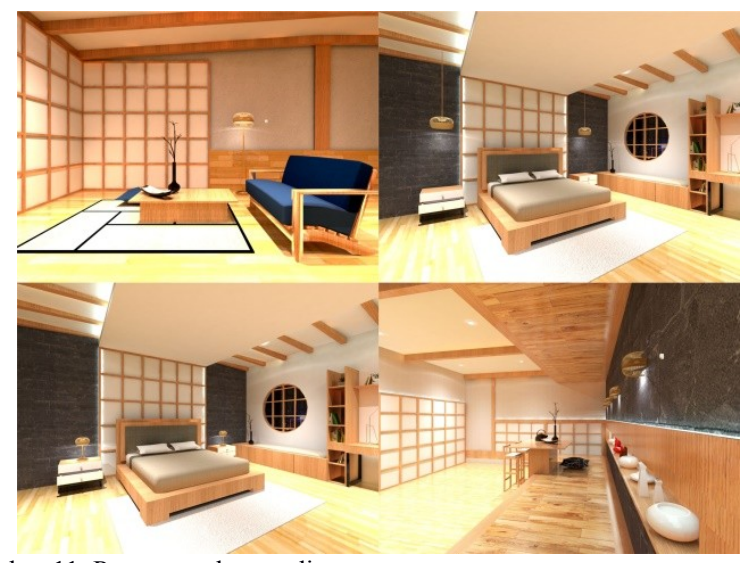

Gambar 11. Penerapan lampu di ruangan.

Penerapan lampu pada area interior ruangan dapat diaplikasikan pada ruang tamu, ruang keluarga, ruang makan, dapur dan kamar. Desain berikut bertumpu pada ruang interior dengan konsep interior gaya Jepang.

\section{KESIMPULAN}

Dalam proses coiling bambu dibutuhkan daya tahan pada bilah bambu yang bisa awet dan tidak mudah rusak. Proses melingkar bambu membutuhkan alat bantu dalam melengkung bambu dan membutuhkan berbagai cetakan dengan diameter dan bentuk yang berbeda. Pewarnaan pada bambu dapat dilakukan dengan pewarna alami dan kimia, warna yang dihasilkan berbeda. Dengan bentuk lilitan bambu bisa diaplikasikan menjadi produk dekorasi rumah, terutama lampu dekorasi rumah. Karena karakteristik bambu yang fleksibel, bambu akan mudah dibentuk menjadi berbagai bentuk desain lampu.

\section{UCAPAN TERIMA KASIH}

Studi ini didukung oleh Amygdala Bamboo sebagai mitra yang mendukung dalam mengumpulkan data.

\section{DAFTAR PUSTAKA}

[1] Kementrian Perindustrian, "Perkembangan Ekspor Indonesia Berdasarkan Sektor," Kelompok Has. Ind., p. 1, 2016.

[2] K. Krawczuk, "Bamboo as sustainable material for future building industry," Copenhagen, 2013.

[3] S. Schröder, "Bamboo Gigantochloa apus," 2014

[4] Anonymous, "The Orign of Coiled Bamboo Bowl A Visit to vietnam," 2015.

[5] Bamboo Craft Indonesia, "What is Bamboo," 2017.

[6] R. F. Latiefa, "Analisis Prototype Sistem Lampu Otomatis Berbasis Arduino Uno yang Terintegrasi dengan Sensor LDR dan Relay," 2016.

[7] Future Market Insight, "Syndicated Market Research Reports,' 2014.

[8] Y. Gunawan, “Jelajah Pesona Garut,” Garut, 2017.

[9] R. Damayanti, "Ketahanan Alami Jenis-jenis Bambu yang Tumbuh di Indonesia terhadap Rayap Tana," 2017. 